\title{
Commentary: It's elementary, my dear Watson
}

Thomas Vierhout, MS, ${ }^{\mathrm{a}}$ and

Meghana R. K. Helder, MD

IBM's Watson, the cognitive artificial intelligence for health care, forced the world to question whether a supercomputer fueled by big data could replace physicians. ${ }^{1}$ Thus far, Watson has overpromised and underdelivered. It doesn't take a Sherlock Holmes to figure out that a clinician's intuition and experience are irreplaceable. However, data packaged in efficient ways, such as validated models, can inform that clinician.

The study by Chen and colleagues ${ }^{2}$ aims to build such a model. They suggest that the inclusion of certain cytokines, specifically interleukin 8 and interleukin 16, along with creatinine builds a model that better predicts cardiac surgery-associated acute kidney injury (CSA-AKI), and as such, provides superior prognostic value for in-hospital outcomes. AKI is the most common major complication following cardiac surgery and is associated with 3- to 8fold higher perioperative mortality, longer intensive care unit stays, and higher costs. ${ }^{3}$ Previous studies have shown that the inclusion of biomarkers can improve the prediction of CSA-AKI. ${ }^{4}$ The ability to interpret all the data and the overall clinical picture of a patient remains an art rather than a science.

With the advent of new technology, we can utilize tools that improve our assessment of a patient and contribute to this art. Through techniques like the machine learning approach used in the current article, large amounts of data can be analyzed and used to inform the clinical experience. Although nothing can replace the experience that comes

From the a University of South Dakota Sanford School of Medicine, Vermillion, SD; and ${ }^{\mathrm{b}}$ Division of Cardiovascular Surgery, North Central Heart Institute, Sioux Falls, SD.

Disclosures: The authors reported no conflicts of interest.

The Journal policy requires editors and reviewers to disclose conflicts of interest and to decline handling or reviewing manuscripts for which they may have a conflict of interest. The editors and reviewers of this article have no conflicts of interest.

Received for publication May 7, 2021; revisions received May 7, 2021; accepted for publication May 10, 2021; available ahead of print May 14, 2021.

Address for reprints: Meghana R. K. Helder, MD, Division of Cardiovascular Surgery, North Central Heart Institute, 4520 W 69th St, Sioux Falls, SD 57108 (E-mail: MHelder@ncheart.com).

J Thorac Cardiovasc Surg 2023;165:1192-3

$0022-5223 / \$ 36.00$

Copyright (C) 2021 by The American Association for Thoracic Surgery

https://doi.org/10.1016/j.jtcvs.2021.05.019

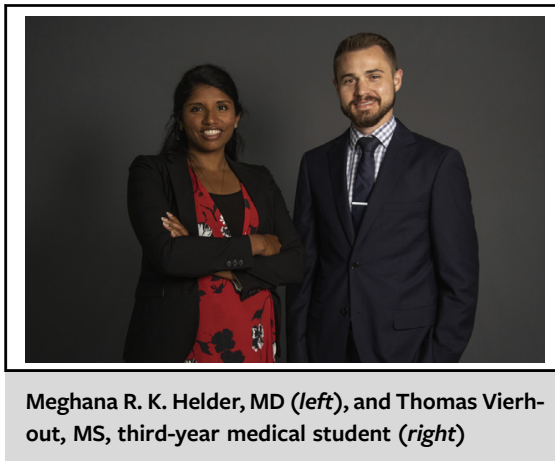

CENTRAL MESSAGE

The use of validated models to

predict complications, such as

acute kidney injury, allows the

use of machine learning to

inform clinician experience and

intuition.

from seeing thousands of patients, the interaction with a patient can be more fruitful when appropriately validated models are used. Observations of a patient can be placed in the broader context provided by the data. The important lessons about which patients may deteriorate can be learned more quickly and help to not only treat that patient but also, with the proper framework, be applied to future patients.

With a better estimate of the risk of hemodialysis after surgery, this model also becomes an important communication tool when informing patients of the potential downstream effects and treatment options for CSA-AKI. To contribute to such an important conversation, the model needs to be validated and trusted. The model presented here was internally validated by a bootstrapping approach and resulted in improved classification of patients at risk for AKI. The model was also validated for predicting renal replacement therapy in an external cohort. Improvements to the model in the future may even provide estimates of how long a patient will need renal replacement therapy, thus giving the patient a more complete understanding of how his or her everyday life might change.

A model to predict CSA-AKI like the one presented in the current article has the potential to inform a physician's clinical interaction, mitigate mortality and cost, 
and improve communication between patient and provider.

\section{References}

1. Miller A. The future of health care could be elementary with Watson. CMAJ. 2013; $185: \mathrm{E} 367-8$
2. Chen Z, Li J, Sun Y, Wang C, Yang W, Ma M, et al. A novel predictive model for poor in-hospital outcomes in patients with acute kidney injury after cardiac surgery. J Thorac Cardiovasc Surg. 2023;165:1180-91.e7.

3. Wang Y, Bellomo R. Cardiac surgery-associated acute kidney injury: risk factors, pathophysiology and treatment. Nat Rev Nephrol. 2017;13:697-711.

4. Parikh CR, Devarajan P, Zappitelli M, Sint K. Thiessen-Philbrook H, Li S, et al. Postoperative biomarkers predict acute kidney injury and poor outcomes after pediatric cardiac surgery. J Am Soc Nephrol. 2011;22:1737-47.
See Article page 1180.

\section{Commentary: Fast is fine, but accurate is essential}

\author{
William L. Holman, MD, Panayotis N. Vardas, MD,
} and James E. Davies, MD

The title of this commentary is an aphorism credited to the famous lawman of the American West, Wyatt Earp. Mr Earp participated in many gunfights, including the shootout at the O.K. Corral in Tombstone, Arizona. The O.K. Corral gunplay lasted less than 30 seconds and each side fired 17 shots. Three of the outlaw cowboys and none of the law officers died. ${ }^{1}$ Wyatt was unharmed and lived until 1929, when he died in Los Angeles at age 80.

In their paper, Chen and associates ${ }^{2}$ present another type of accuracy; namely, accuracy of a mathematical model that identifies patients early after cardiac surgery who will develop acute kidney injury and are at risk for postoperative mortality. Their model was developed with sophisticated statistical methods, including machine learning. It identified 2 cytokines (interleukin- 8 and interleukin-16) from a panel of 32 candidate cytokines together with the change in serum creatinine level from preoperative to early postoperative as variables for a

From the Division of Cardiothoracic Surgery, Department of Surgery, University of Alabama at Birmingham, Birmingham, Ala.

Disclosures: Dr Holman serves on data and safety monitoring boards for Abbott and Medtronic; Dr Davies is a consultant for Medtronic and Edwards; and Dr Vardas reported no conflicts of interest.

The Journal policy requires editors and reviewers to disclose conflicts of interest and to decline handling or reviewing manuscripts for which they may have a conflict of interest. The editors and reviewers of this article have no conflicts of interest.

Received for publication May 7, 2021; revisions received May 7, 2021; accepted for publication May 7, 2021; available ahead of print May 11, 2021.

Address for reprints: William L. Holman, MD, Division of Cardiothoracic Surgery, Department of Surgery, University of Alabama at Birmingham, 703 19th St South,

Room 719, Birmingham, AL 35294 (E-mail: wlholman@uabmc.edu).

J Thorac Cardiovasc Surg 2023;165:1193-4

0022-5223/\$0.00

Published by Elsevier Inc. on behalf of The American Association for Thoracic Surgery

https://doi.org/10.1016/j.jtcvs.2021.05.013

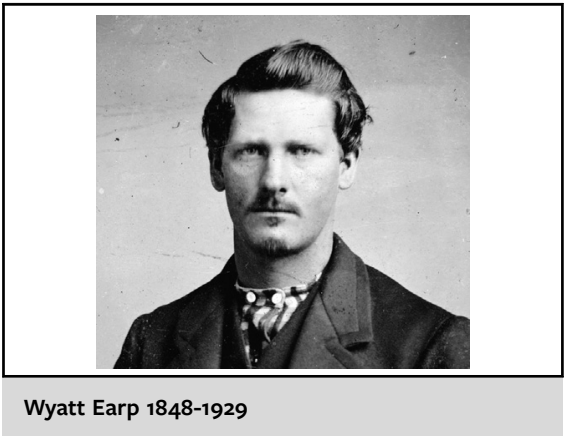

CENTRAL MESSAGE

The authors created a nomo-

gram that uses measurements of

2 cytokines together with peri-

operative change in serum

creatinine to predict postopera-

tive renal injury in cardiac surgery

patients.

predictive nomogram. The model was generated from a group of patients at one hospital and validated in patients at another hospital. The nomogram for prediction of the composite outcome (Figure 3, A, with link to an online calculator) performed well in the training and the validation cohorts (Table 4).

What can we do with this information? The authors provide an answer in Figure 3, $B$, by comparing the projected outcomes from an accurate prediction (labeled nomogram) to strategies of treating all patients at risk or none of the patients at risk for acute kidney injury.

There is potential benefit from the accurate identification of patients who are early in the evolution of postoperative nephropathy. ${ }^{3}$ Delayed treatment of patients with renal failure places them at risk for fluid overload and possibly other problems. In similar fashion, there are costs and risks associated with a treat-all strategy for renal 